Research Article

\title{
Utilization of Response Surface Methodology in Optimization of Polysaccharides Extraction from Vietnamese Red Ganoderma lucidum by Ultrasound-Assisted Enzymatic Method and Examination of Bioactivities of the Extract
}

\author{
Dat Tran Do, ${ }^{1}$ Dang Hoang Lam, ${ }^{2}$ Tai Nguyen, ${ }^{2}$ Tran Thi Phuong Mai, ${ }^{2}$ Le Thao My Phan, \\ Hoai Thanh Vuong, ${ }^{1}$ Duc Viet Nguyen, ${ }^{2}$ Ngo Thi Thuy Linh, ${ }^{1}$ Minh Nam Hoang, ${ }^{2,3}$ \\ Thanh Phong Mai, ${ }^{2,3}$ and Huu Hieu Nguyen $\mathbb{D I D}^{1,2,3}$ \\ ${ }^{1}$ VNU-HCMC Key Laboratory of Chemical Engineering and Petroleum Processing (CEPP Lab), Ho Chi Minh City, Vietnam \\ ${ }^{2}$ Faculty of Chemical Engineering, Ho Chi Minh City University of Technology, 268 Ly Thuong Kiet Street, Ward 14, District 10, \\ Ho Chi Minh City, Vietnam \\ ${ }^{3}$ Vietnam National University Ho Chi Minh City, Linh Trung Ward, Thu Duc District, Ho Chi Minh City, Vietnam
}

Correspondence should be addressed to Huu Hieu Nguyen; nhhieubk@hcmut.edu.vn

Received 10 August 2020; Revised 14 October 2020; Accepted 27 January 2021; Published 11 February 2021

Academic Editor: Nirmal Kumar Sarkar

Copyright (C) 2021 Dat Tran Do et al. This is an open access article distributed under the Creative Commons Attribution License, which permits unrestricted use, distribution, and reproduction in any medium, provided the original work is properly cited.

Red Ganoderma lucidum (G. lucidum) is a popular medicinal herb commonly used in Vietnamese traditional remedies due to its potential value for health. In this study, polysaccharides were extracted from G. lucidum using ultrasound-assisted enzymatic extraction method. The response surface methodology and Box-Behnken design were employed to investigate the effects of $\mathrm{pH}$, extraction temperature, extraction time, and ultrasonic power on the content of polysaccharides. Based on ultraviolet-visible spectroscopy analysis, the highest content of polysaccharides in the extract was $32.08 \mathrm{mg} / \mathrm{g}$ under optimum experimental parameters including enzyme concentration of $3 \%, \mathrm{pH}$ of 5.5, extraction temperature of $45^{\circ} \mathrm{C}$, extraction time of $30 \mathrm{~min}$, and ultrasonic power of $480 \mathrm{~W}$. The Fourier-transform infrared spectroscopy was also used to identify the functional groups in the extracts. The molecular weights of polysaccharides were determined by gel permeation chromatography. The obtained extract was then evaluated for anticancer activities by using (3-(4,5-dimethylthiazol-2-yl)-2,5-diphenyltetrazolium bromide) assay, showing the anticancer activities with the half-maximal inhibitory concentration value of more than $512 \mu \mathrm{g} / \mathrm{mL}$. This result suggested that UAEE could be considered as an appropriate and effective extraction method for bioactive crude polysaccharides from G. lucidum.

\section{Introduction}

Ganoderma lucidum (G. lucidum), which is known as Lingzhi in China, is a basidiomycete fungus belonging to the Polyporaceae family. It is widely used in China as a remedy for minor health disorders to promote vitality and longevity. In East Asia, it has been long used to treat many diseases such as nephritis, chronic hepatitis, gastric ulcers, arthritis, neurasthenia, bronchitis, asthma, and hypertension in oriental countries [1-5]. Recent studies on G. lucidum have shown that it has numerous bioactivities, including anticancer, antioxidant, and immunomodulating effects $[6,7]$. To gain insights into the mechanisms of polysaccharides and triterpenoids for health benefits, their effects on various human cell lines have been investigated extensively [8-13]. With the objective of obtaining extracts with higher yields and lower costs, various methods of extraction have been developed. Among them, the ultrasound-assisted extraction (UAE) method and enzyme-assisted extraction (EAE) method have become ideal alternatives to traditional techniques because of their efficiency and environment friendliness. It is reported that while EAE requires long 
extraction time, the capability of enzyme could be enhanced by ultrasonic wave. Therefore, ultrasonic-assisted enzymatic extraction (UAEE) could be used for polysaccharide extraction from $G$. lucidum so that a higher content of polysaccharide can be achieved in shorter extraction time.

Composed of monosaccharide unit long chains linked by glycosidic bonds, polysaccharides are polymeric carbohydrate molecules [14]. Gel permeation chromatography (GPC) was widely applied for characterization of polysaccharides with identification of molecular weight averages and molecular weight distributions offering numerous advantages $[15,16]$. In this study, polysaccharides were extracted from G. lucidum using UAEE method. Response surface methodology (RSM) was used to optimize the extraction conditions including $\mathrm{pH}$, extraction temperature, extraction time, and ultrasonic power. Under optimum extraction conditions, the extract obtained was then investigated by using the Fourier-transform infrared spectroscopy (FTIR) and the GPC, followed by the anticancer activity evaluation for three lines of $\mathrm{KB}$, HepG2, and Lu cancer cells.

\section{Materials and Methods}

2.1. Material and Chemicals. Dried fruiting bodies of Vietnamese Red G. lucidum in maturity stage with mature spores were stored in closed plastic bag and were supplied by Linhchivina Co., JSC (Vietnam).

Viscozyme was purchased from Novozymes, Denmark, chitinase was purchased from Sigma-Aldrich, and 95.0\% and 99.5\% ethanol were purchased from Chemsol. 99.0\% D-glucose, $99.5 \%$ sodium hydrogen phosphate $\left(\mathrm{Na}_{2} \mathrm{HPO}_{4}\right)$, 99.5\% sodium tetraborate decahydrate $\left(\mathrm{Na}_{2} \mathrm{~B}_{4} \mathrm{O}_{7} .10 \mathrm{H}_{2} \mathrm{O}\right)$, $37.0 \%$ hydrochloric acid $(\mathrm{HCl}), 99.5 \%$ phenol, $98.0 \%$ sulfuric acid, $99.0 \%$ citric acid, and $99.7 \%$ ascorbic acid were purchased from Xylong, China.

2.2. Extraction Methods. $5.0 \mathrm{~g}$ of fungus powder was dispersed in $100 \mathrm{~mL}$ of distilled water, followed by the addition of $100 \mu \mathrm{L}$ of the mixture of enzymes including vicozyme and chitinase with a ratio of $1: 1$. The extraction conditions including $\mathrm{pH}$ value, extraction temperature, extraction time, and ultrasonic power were set based on the experimental design. After filtration, the solvent was partially removed by using vacuum evaporation at $65-70^{\circ} \mathrm{C}$. The concentration was then precipitated with the addition of $100 \mathrm{~mL} 99.5 \%$ ethanol at $4^{\circ} \mathrm{C}$ in 12 hours. Next, the mixture was centrifuged, and the precipitate was collected before being dried to obtain the crude polysaccharides. According to reported research, the crude polysaccharides were preliminarily purified using the Sevag method for deproteinization of the extract [17]. First, the Sevag solution including $n$-butanol and chloroform with the ratio of $1: 4$ was prepared. After the addition of the Sevag solution to obtain polysaccharide aqueous extract, the mixture was gently shaken and allowed to be settled for the phases to separate. The supernatant was collected and precipitated by adding $96 \%$ ethanol with a proportion of $1: 4$ at $4^{\circ} \mathrm{C}$ for 24 hours and then centrifuged at
$12000 \mathrm{rpm}$ for $20 \mathrm{~min}$. Subsequently, the achieved precipitate was dried at $60^{\circ} \mathrm{C}$. The procedure was repeated 3 times or more for the removal of the protein. Figure 1 shows the image of red G. lucidum provided by Linhchivina Co., JSC (Vietnam).

2.3. Box-Behnken Design and Statistical Analysis. From the result of single factor experiments on the content of polysaccharides, four factors having the most influence on the content of polysaccharides and the experimental variable ranges of these factors were determined according to previous studies [18]. The experiments were conducted based on three-level Box-Behnken design. Four independent variables including $\mathrm{pH}$, extraction temperature, extraction time, and ultrasonic power were designated as $X_{1}, X_{2}, X_{3}$, and $X_{4}$, respectively. Table 1 shows the independent variables and their levels.

2.4. Determination of the Polysaccharide Content. The phenol-sulfuric acid colorimetric method was used to determine content of polysaccharides with $\mathrm{D}$-glucose as standard solution. Six standard D-glucose solutions including 50, 100, $200,300,400$, and $500 \mu \mathrm{g} / \mathrm{mL}$ were prepared from D-glucose solution with concentration of $1000 \mu \mathrm{g} / \mathrm{mL}$. Then, $1 \mathrm{~mL}$ of each standard solution was removed and transferred to a volumetric flask $(20 \mathrm{~mL})$, followed by the addition of $1 \mathrm{~mL}$ of $5 \%$ phenol solution and $5 \mathrm{~mL}$ of $98 \%$ concentrated sulfuric acid. In addition, $1 \mathrm{~mL}$ of distilled water was added to $1 \mathrm{~mL}$ of $5 \%$ phenol solution and $5 \mathrm{~mL}$ of $98 \%$ concentrated sulfuric acid to prepare blank solution whereas the extract solution was prepared by the addition of $1 \mathrm{~mL}$ of the extract, $1 \mathrm{~mL}$ of $5 \%$ phenol solution, and $5 \mathrm{~mL}$ of $98 \%$ concentrated sulfuric acid. After $30 \mathrm{~min}$, the measurement of absorbance was conducted at $488 \mathrm{~nm}$. The content of polysaccharides was determined according to the absorbance of the extract solution and baseline.

\subsection{Fourier-Transform Infrared Spectroscopy Analysis.} The FTIR measurements were carried out at VNU-HCMC Key Laboratory of Chemical Engineering and Petroleum Processing (CEPP Lab), Ho Chi Minh City University of Technology-Vietnam National University Ho Chi Minh City (HCMUT-VNUHCM), with the FTIR spectrometer Alpha II from Bruker, Germany. For FT-IR measurement, the polysaccharides were ground with $\mathrm{KBr}$ powder and pressed into pellets. The frequency range used was $4000-400 \mathrm{~cm}^{-1}$ to detect functional groups.

2.6. Gel Permeation Chromatography. The molecular weights of polysaccharides were determined by the GPC, in combination with a high-performance liquid chromatography instrument (Angilent1100, USA) equipped with an Ultrahydrogel column. The experiments were conducted at the Central Laboratory for Analysis (CLA), Ho Chi Minh City University of Science-Vietnam National University Ho Chi Minh City (HCMUS-VNUHCM). 


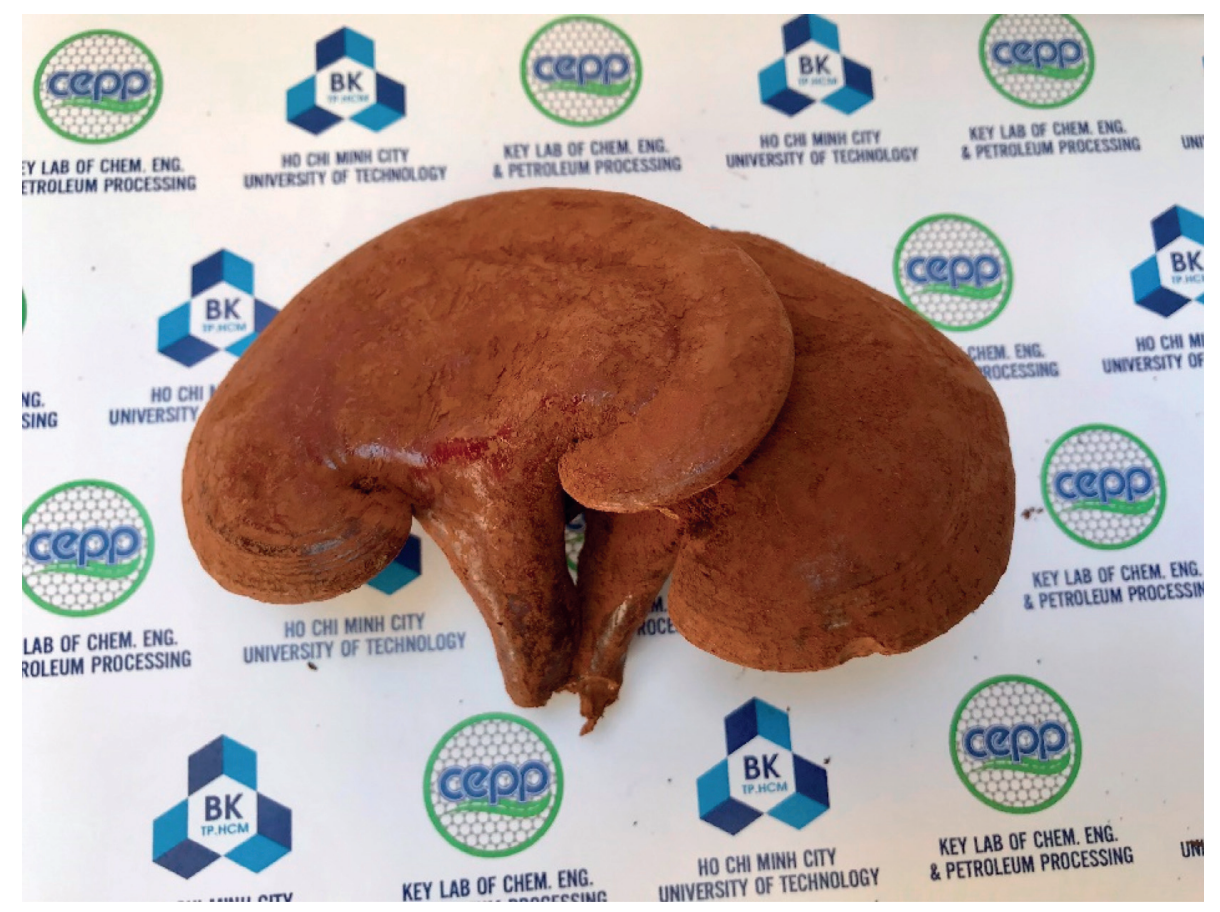

FIGURE 1: Image of Vietnamese red G. lucidum.

TABLE 1: Independent variables and their levels.

\begin{tabular}{lccccc}
\hline \multirow{2}{*}{ Independent variables } & \multirow{2}{*}{ Unit } & Code & \multicolumn{3}{c}{ Levels } \\
& & & -1 & 0 & 1 \\
\hline $\mathrm{pH}$ & & $X_{1}$ & 6 & 8 & 10 \\
Extraction temperature & ${ }^{\circ} \mathrm{C}$ & $X_{2}$ & 30 & 50 & 70 \\
Extraction time & $\mathrm{min}$ & $X_{3}$ & 40 & 120 & 200 \\
Ultrasonic power & $\mathrm{W}$ & $X_{4}$ & 120 & 360 & 600 \\
\hline
\end{tabular}

The column temperature was maintained at $30^{\circ} \mathrm{C}$. Samples were filtered through a $0.45 \mu \mathrm{m}$ filter and the injection volume was $20 \mu \mathrm{L}$. The mobile phase was $0.1 \mathrm{M}$ in potassium nitrate, and the flow rate was $1.0 \mathrm{~mL} / \mathrm{min}$ and detected by a refractive index detector $[19,20]$.

2.7. Anticancer Activities of the Extract. The anticancer capacity of the extract was evaluated by using 3-(4,5-dimethylthiazol-2-yl)-2,5-diphenyltetrazolium bromide (MTT) assay against cell lines including KB oral squamous cell carcinoma, liver cancer cell line HepG2, and lung cancer cell line Lu-1. The experiments were conducted at Laboratory of Applied Biochemistry-Institute of ChemistryVietnam Academy of Science and Technology. $190 \mu \mathrm{L}$ of the cell solution was mixed with $10 \mu \mathrm{L}$ of the extract sample. The control tests included the positive control which contained the cancer cells and the negative control which was the cultural medium after 72 hours of incubation.

Each sample was then added to $10 \mu \mathrm{L}$ of $5 \mathrm{mg} / \mathrm{mL}$ MTT solution and incubated for 4 hours. Finally, the sample was separated from media and formazan crystal was dissolved into $100 \mu \mathrm{L}$ of absolute DMSO solution. The absorbance was measured at $540 \mathrm{~nm}$ by Genios Tecan spectrograph and the $\mathrm{IC}_{50}$ value was calculated by the $\%$ cell inhibition.

\section{Results and Discussion}

3.1. Experimental Design. Twenty-seven randomized experimental runs were conducted. Table 2 presents the variable conditions used in each experimental assay.

By multiple regression analysis on the experimental data, the predicted response on content of polysaccharides and the test variables were related by equation (1) showing quadratic polynomial model based on actual value:

$$
\begin{aligned}
Y= & 32.4+0.67 X_{1}+1.58 X_{2}+0.77 X_{3}-0.85 X_{4} \\
& -0.51 X_{1} X_{2}-0.07 X_{1} X_{3}-0.30 X_{1} X_{4}-0.21 X_{2} X_{3} \\
& -0.67 X_{2} X_{4}-0.34 X_{3} X_{4}-5.43 X_{1}^{2}-5.86 X_{2}^{2} \\
& -4.11 X_{3}^{2}-3.47 X_{4}^{2},
\end{aligned}
$$

where $Y(\mathrm{mg} / \mathrm{g})$ is the content of polysaccharides and four variables including $X_{1}, X_{2}, X_{3}$, and $X_{4}$ are $\mathrm{pH}$, extraction temperature $\left({ }^{\circ} \mathrm{C}\right)$, extraction time $(\mathrm{min})$, and ultrasonic power $(\mathrm{W})$.

Table 3 illustrates the analysis of variance (ANOVA) for the response surface quadratic model, and $F$ value and $p$ value were used to check the statistical significance of the regression equation. Evident from Fisher's $F$ test with a high model $F$ value $(30.95)$ but a low $p$ value $(p<0.0001)$, ANOVA of quadratic regression model showed that the model was highly significant and had a good fit of the model. The determination coefficient $\left(R^{2}=0.97\right)$ was used to evaluate the goodness-of-fit of the model, showing that only 
TABLE 2: Factors and levels for RSM, and Box-Behnken design with the independent variables.

\begin{tabular}{|c|c|c|c|c|c|c|}
\hline \multirow{2}{*}{ Run $X$} & \multirow{2}{*}{$X_{1}$} & \multirow{2}{*}{$X_{2}$} & \multirow{2}{*}{$X_{3}$} & \multirow{2}{*}{$X_{4}$} & \multicolumn{2}{|c|}{$Y$} \\
\hline & & & & & Experimental & Predicted \\
\hline 1 & 0 & 0 & -1 & -1 & 24.3 & 24.5 \\
\hline 2 & -1 & -1 & 0 & 0 & 17.5 & 18.3 \\
\hline 3 & 0 & 0 & 0 & 0 & 32.5 & 32.4 \\
\hline 4 & -1 & 0 & 0 & -1 & 23.2 & 23.3 \\
\hline 5 & 0 & 0 & 1 & -1 & 26.0 & 26.7 \\
\hline 6 & 1 & 1 & 0 & 0 & 22.4 & 22.9 \\
\hline 7 & 0 & 1 & -1 & 0 & 24.2 & 23.4 \\
\hline 8 & -1 & 1 & 0 & 0 & 22.2 & 22.5 \\
\hline 9 & -1 & 0 & 0 & 1 & 23.0 & 22.3 \\
\hline 10 & 1 & 0 & 0 & -1 & 25.7 & 25.3 \\
\hline 11 & 0 & 1 & 0 & -1 & 26.3 & 26.1 \\
\hline 12 & -1 & 0 & -1 & 0 & 21.2 & 21.3 \\
\hline 13 & 1 & -1 & 0 & 0 & 19.8 & 20.7 \\
\hline 14 & 0 & 0 & 0 & 0 & 32.0 & 32.4 \\
\hline 15 & 0 & -1 & 1 & 0 & 22.2 & 21.8 \\
\hline 16 & -1 & 0 & 1 & 0 & 23.7 & 23.1 \\
\hline 17 & 1 & 0 & 1 & 0 & 24.6 & 24.3 \\
\hline 18 & 0 & -1 & 0 & -1 & 22.4 & 21.5 \\
\hline 19 & 0 & 1 & 1 & 0 & 25.0 & 24.6 \\
\hline 20 & 1 & 0 & -1 & 0 & 22.3 & 22.9 \\
\hline 21 & 0 & -1 & -1 & 0 & 20.5 & 19.8 \\
\hline 22 & 0 & 1 & 0 & 1 & 22.6 & 23.1 \\
\hline 23 & 1 & 0 & 0 & 1 & 24.2 & 23.1 \\
\hline 24 & 0 & 0 & 0 & 0 & 32.6 & 32.4 \\
\hline 25 & 0 & 0 & 1 & 1 & 23.4 & 24.5 \\
\hline 26 & 0 & 0 & -1 & 1 & 23.1 & 23.5 \\
\hline 27 & 0 & -1 & 0 & 1 & 21.3 & 21.3 \\
\hline
\end{tabular}

TABLE 3: ANOVA for the second-order polynomial model.

\begin{tabular}{|c|c|c|c|c|c|c|}
\hline Source & Sum of squares & Degree of freedom & Mean squares & $F$ value & $p$ value & \\
\hline Model & 322.30 & 14 & 23.02 & 30.95 & $<0.0001$ & Significant \\
\hline$X_{1}-\mathrm{pH}$ & 5.52 & 1 & 5.52 & 7.52 & 0.0185 & \\
\hline$X_{2}$-extraction temperature & 29.94 & 1 & 29.94 & 40.24 & $<0.0001$ & \\
\hline$X_{3}$-extraction time & 7.16 & 1 & 7.16 & 9.63 & 0.0091 & \\
\hline$X_{4}$-ultrasonic power & 8.58 & 1 & 8.58 & 11.53 & 0.0053 & \\
\hline$X_{1} X_{2}$ & 1.04 & 1 & 1.04 & 1.40 & 0.2603 & \\
\hline$X_{1} X_{3}$ & 0.0172 & 1 & 0.0172 & 0.0232 & 0.8816 & \\
\hline$X_{1} X_{4}$ & 0.3634 & 1 & 0.3634 & 0.4885 & 0.4979 & \\
\hline$X_{2} X_{3}$ & 0.1767 & 1 & 0.1767 & 0.2376 & 0.6347 & \\
\hline$X_{2} X_{4}$ & 1.79 & 1 & 1.79 & 2.40 & 0.1470 & \\
\hline$X_{3} X_{4}$ & 0.4639 & 1 & 0.4639 & 0.6236 & 0.4450 & \\
\hline$X 12$ & 156.96 & 1 & 156.96 & 211.00 & $<0.0001$ & \\
\hline$X 22$ & 183.41 & 1 & 183.41 & 246.55 & $<0.0001$ & \\
\hline$X 32$ & 89.93 & 1 & 83.93 & 120.89 & $<0.0001$ & \\
\hline$X 42$ & 64.35 & 1 & 64.35 & 86.51 & $<0.0001$ & \\
\hline Residual & 8.93 & 12 & 0.7439 & & & \\
\hline Lack of fit & 8.73 & 10 & 0.8730 & 8.88 & 0.1053 & Not significant \\
\hline Pure error & 0.1965 & 2 & 0.0863 & & & \\
\hline Cor total & 331.23 & 26 & & & & \\
\hline$R 2$ & 0.9730 & SD & 0,0863 & & & \\
\hline $\mathrm{Adj}-R^{2}$ & 0.9416 & C.V \% & 3.59 & & & \\
\hline Pred- $R^{2}$ & 0.8468 & & & & & \\
\hline Adep. precision & 21.8652 & & & & & \\
\hline
\end{tabular}


$3.14 \%$ of the total variations could not be explained by the model. Moreover, Pre- $R^{2}$ is 0.8468 , which was smaller and very closed to $\operatorname{Adj}-R^{2}$, which was of 0.94 (Adj- $R^{2}$-Pre- $R^{2}$ $<0.2$ ), presenting a high correlation degree between the observed and predicted data from the regression model [21]. In addition, the low value of coefficient of the variation (C.V. $\%$ ) of $3.59 \%$ for the content of polysaccharides represented the dispersion of data points was around the mean and had a good reliability. The linear coefficients $X_{1}, X_{2}, X_{3}, X_{4}$ and the quadratic coefficients $X_{1}^{2}, X_{2}^{2}, X_{3}^{2}$, and $X_{4}^{2}$ had significant effects on content of polysaccharides $(p<0.05)$. The other coefficient influences on content of polysaccharides were not significant $(p>0.05)$.

The impacts of independent variables and their mutual interaction on the yield of polysaccharides can be evaluated and visualized by response surface and contour plots as shown in Figures 2-7 by employing the software DesignExpert (Version 11.0, Stat-Ease Inc., Minneapolis, MN, USA). It could be deduced based on Figure 1 that the optimum conditions for extraction procedure were predicted including extraction time of $127.69 \mathrm{~min}$, extraction temperature of $52.78^{\circ} \mathrm{C}$, ultrasonic power of $325.99 \mathrm{~W}$, and $\mathrm{pH}$ value of 8.12 .

\subsection{Simultaneous Effect of Extraction Conditions}

3.2.1. Effect of $p H$ and Extraction Temperature on the Content of Polysaccharides. Figure 2 shows the simultaneous effects of $\mathrm{pH}$ and extraction temperature on content of polysaccharides when ultrasonic power was kept with the value of $360 \mathrm{~W}$ and extraction time was of the value of $120 \mathrm{~min}$. It is clearly seen that, with the increase of extraction temperature and $\mathrm{pH}$ value, content of polysaccharides was increased dramatically. This could be explained that when the $\mathrm{pH}$ and the extraction temperature were not too high, the impact of enzyme and high ultrasonic power efficiently broke the structure of the cell wall, leading to the diffusion of content of polysaccharides into solvent. However, at high $\mathrm{pH}(>8.2)$ and high temperature $\left(>52^{\circ} \mathrm{C}\right)$, the yield of polysaccharides experienced a decrease because polysaccharides were reported to be more likely to be hydrolyzed under these conditions $[22,23]$. This result is suitable with a previous study [24].

\subsubsection{Effect of $p H$ and Extraction Time on the Content of} Polysaccharides. Figure 3 illustrates the simultaneous effects of $\mathrm{pH}$ and extraction time on content of polysaccharides while the ultrasonic power was of $360 \mathrm{~W}$ and extraction temperature was of $50^{\circ} \mathrm{C}$. It is clearly seen that the increase of $\mathrm{pH}$ value and extraction time led to the increase of the content of polysaccharides. The content of polysaccharides was slightly decreased when the $\mathrm{pH}$ value reached 7.8 with the extraction time of over $120 \mathrm{~min}$. It is stated that although longer extraction time could facilitate the extraction process, this could lead to processes of oxidation and degradation of polysaccharide $[25,26]$. This result, therefore, can be found similar to the other studies $[23,24,27]$.
3.2.3. Effect of $\mathrm{pH}$ and Ultrasonic Power on the Content of Polysaccharides. Figure 4 demonstrates the simultaneous effects of $\mathrm{pH}$ and ultrasonic power on content of polysaccharides while the extraction time was of $120 \mathrm{~min}$ and extraction temperature was of $50^{\circ} \mathrm{C}$. The high content of polysaccharides obtained at ultrasonic power ranged from 280 to $400 \mathrm{~W}$ and $\mathrm{pH}$ ranged between 7.5 and 8.5. The increase in ultrasonic power and $\mathrm{pH}$ level could facilitate the destruction of cell wall, leading to the diffusion of solvent through cell walls to release polysaccharides. However, when the ultrasonic power was higher than $400 \mathrm{~W}$, enzyme could be inactivated and the cavitation effect could be weakened $[28,29]$. This result is in agreement with the result reported in previous research $[23,24,26]$.

\subsubsection{Effect of Extraction Temperature and Extraction Time} on the Content of Polysaccharides. Figure 5 presents the mutual interactions of extraction temperature and extraction time on content of polysaccharides., where the ultrasonic power was kept at $360 \mathrm{~W}$ and $\mathrm{pH}$ value was of 8.0. As shown in Figure 5, the content of polysaccharides significantly increased as the extraction time was raised from 40 to $120 \mathrm{~min}$ and the extraction temperature increased from 30 to $48^{\circ} \mathrm{C}$. The longer the extraction time was, the higher the diffusion capacity of the active ingredient was. Nevertheless, when extraction temperature was over $48^{\circ} \mathrm{C}$ and extraction time longer than $120 \mathrm{~min}$, the content of polysaccharides decreased gradually. This could be explained by the fact that when extraction time and extraction temperature exceed the values, the hydrolysis of polysaccharides tends to happen vigorously, leading to a decrease in the content of polysaccharides according to reported experiments [20, 23, 27].

\subsubsection{Effect of Extraction Temperature and Ultrasonic Power} on the Content of Polysaccharides. Figure 6 describes the simultaneous effects of extraction temperature and ultrasonic power on content of polysaccharides. The content of polysaccharides increased considerably in the extraction temperature which ranged from 45 to $55^{\circ} \mathrm{C}$ and ultrasonic power which ranged between $220 \mathrm{~W}$ and $400 \mathrm{~W}$. Earlier reports indicated that wave could improve mass transfer, enhancing the efficiency of substrate delivery to the active sites of the enzymes [23, 27, 30-32].

\subsubsection{Effect of Extraction Time and Ultrasonic Power on the} Content of Polysaccharides. The simultaneous effects of extraction time and ultrasonic power on content of polysaccharides are as shown in Figure 7, where the extraction temperature was kept at $50^{\circ} \mathrm{C}$ and $\mathrm{pH}$ value was of 8.0. From Figure 7 , it is clear that the content of polysaccharides was low when extraction time ranged between 40 and $80 \mathrm{~min}$ and ultrasonic power ranged between 120 and $240 \mathrm{~W}$. The increase in extraction power facilitates the disruption of the cell walls, enhances the presented compounds solubility, and increases the extraction yield [20]. Moreover, higher ultrasonic power and longer extraction time lead to slight increase in the content of polysaccharides. It was reported 


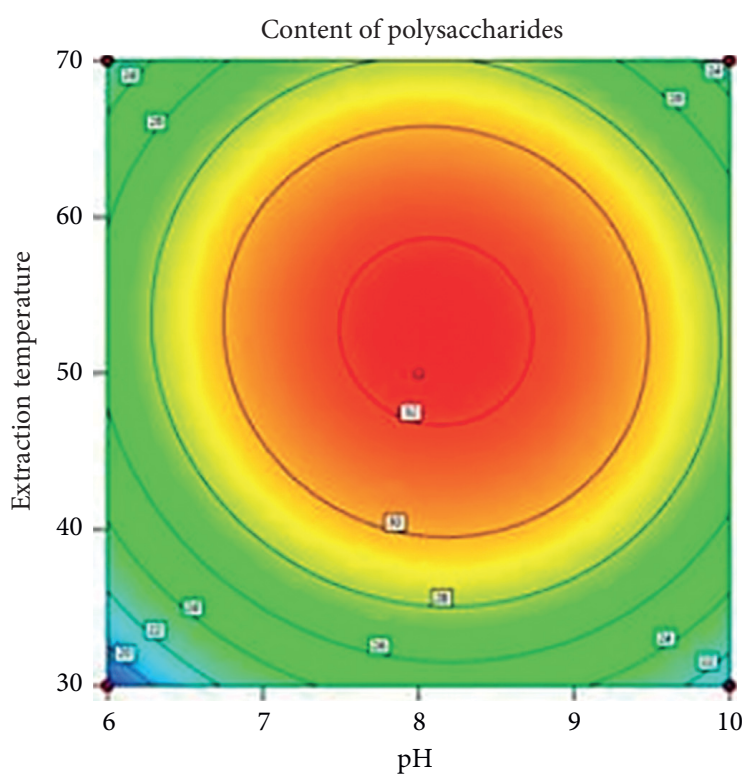

(a)

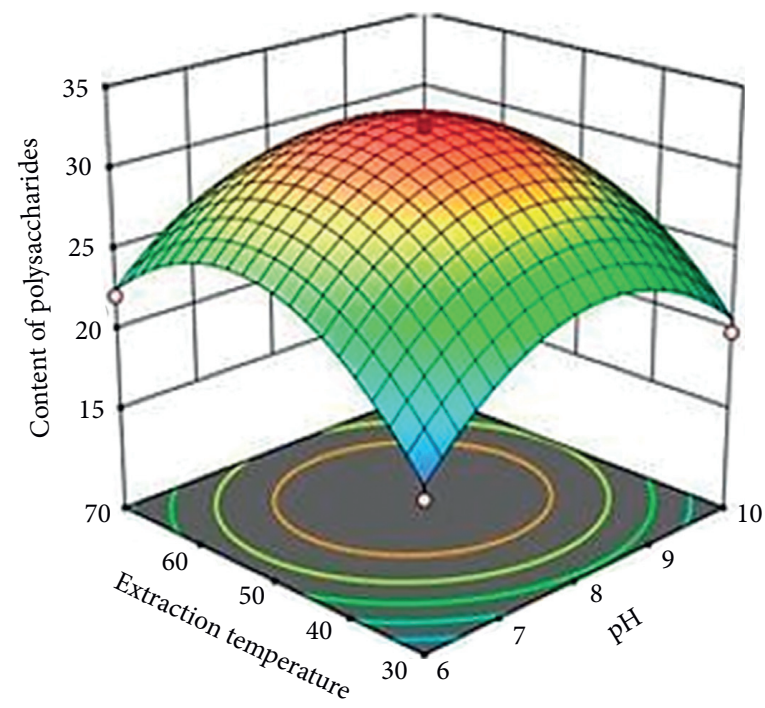

(b)

FIgURE 2: Simultaneous effect of $\mathrm{pH}$ and extraction temperature on the content of polysaccharides.

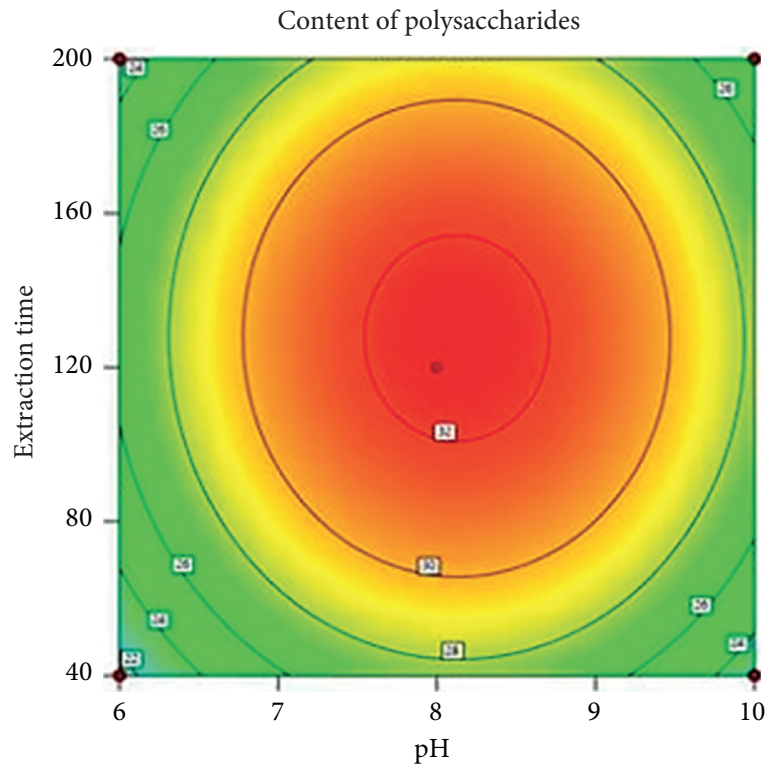

(a)

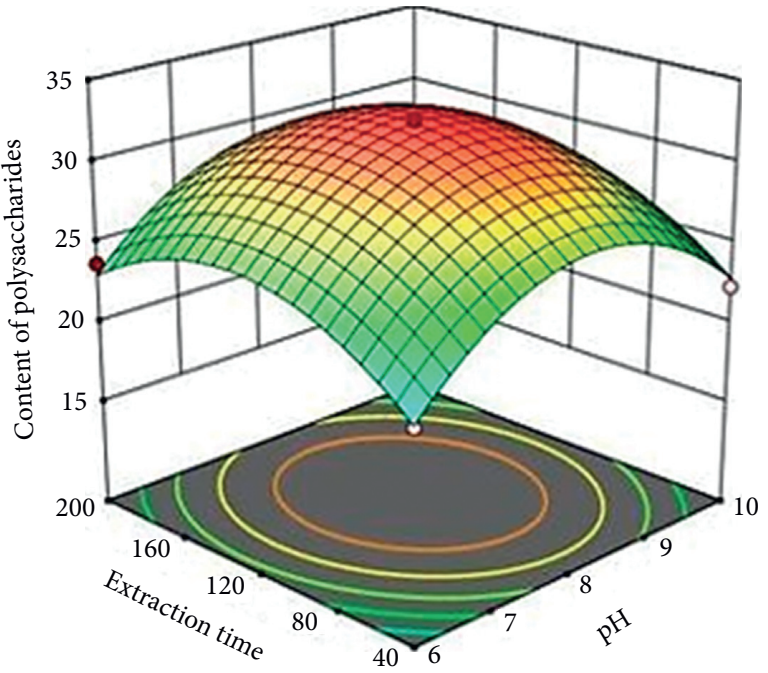

(b)

Figure 3: Simultaneous effect of $\mathrm{pH}$ and extraction time on the content of polysaccharides.

that prolonged extraction time could cause saturation between solvent and substrates while polysaccharides could be degraded under the influence of high ultrasonic power $[26,27,33]$.

To meet the actual conditions operability, predicted and experimental optimum extraction conditions are as shown in Table 4. Under these conditions, the experimental content of polysaccharides was $32.08 \mathrm{mg} / \mathrm{g}$, which was in good agreement with the prediction of $32.63 \mathrm{mg} / \mathrm{g}$.
3.3. Fourier-Transform Infrared Spectroscopy Analysis. Figure 8 illustrates the FT-IR spectrum of polysaccharides in order to confirm characteristics of polysaccharides. The broad band around $3318 \mathrm{~cm}^{-1}$ was caused by O-H stretching vibration. Meanwhile, the band at $2972 \mathrm{~cm}^{-1}$ corresponded to the $\mathrm{C}-\mathrm{H}$ absorption of $-\mathrm{CH}_{2}$ in polysaccharides structures. The peak at $1044 \mathrm{~cm}^{-1}$ revealed the presence $\mathrm{C}=\mathrm{O}$ stretching vibration. The existence of a weak absorption band at $1620 \mathrm{~cm}^{-1}$ was typical of glycosidic bonds in 


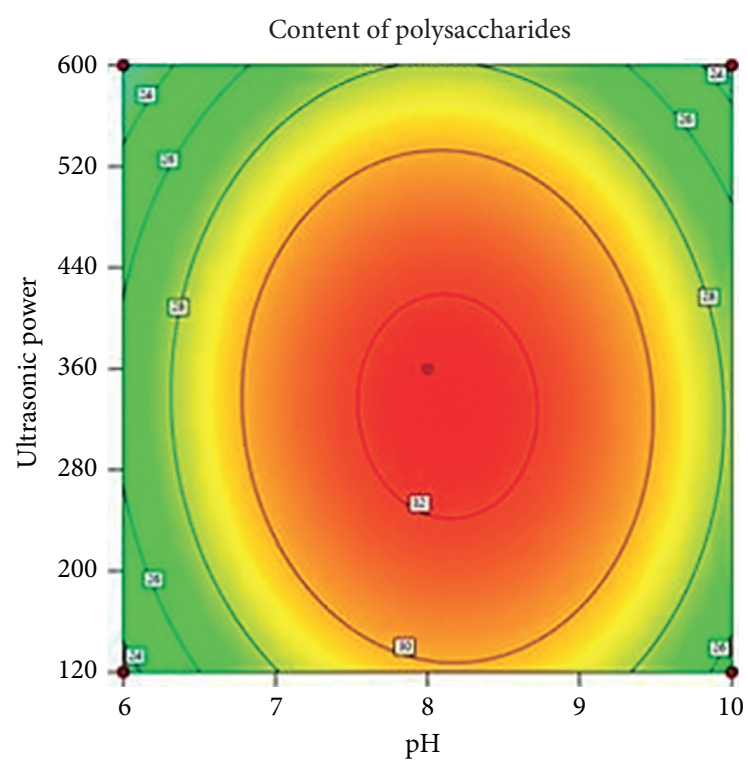

(a)

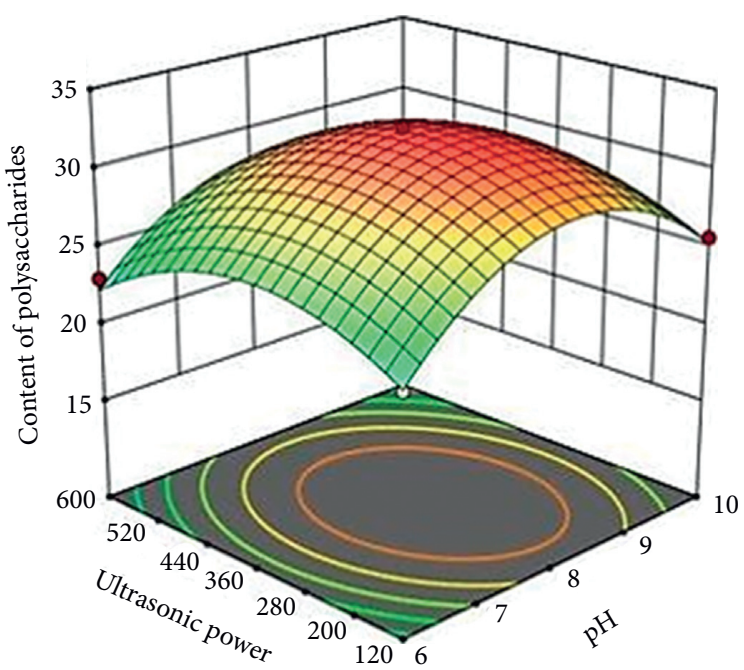

(b)

FIGURE 4: Simultaneous effect of $\mathrm{pH}$ and ultrasonic power on the content of polysaccharides.

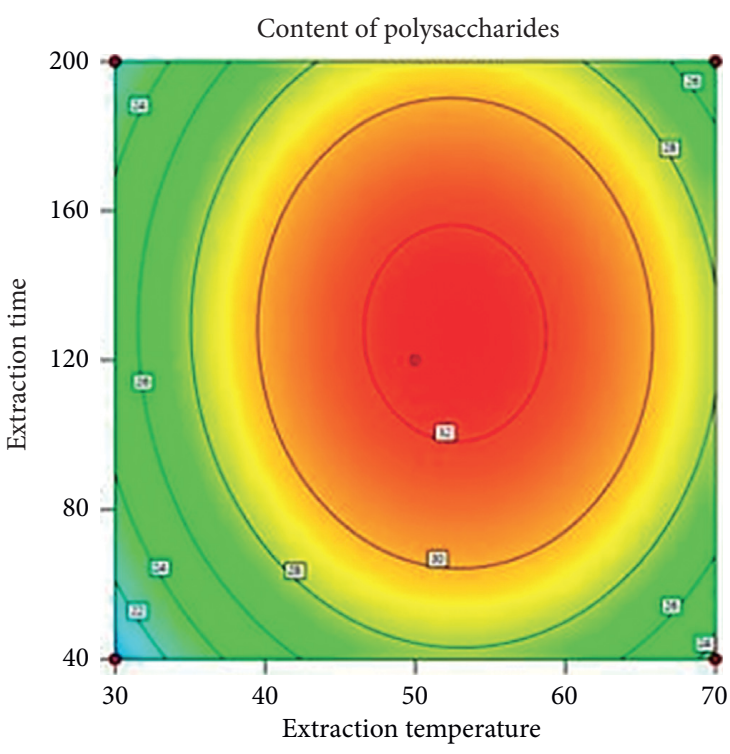

(a)

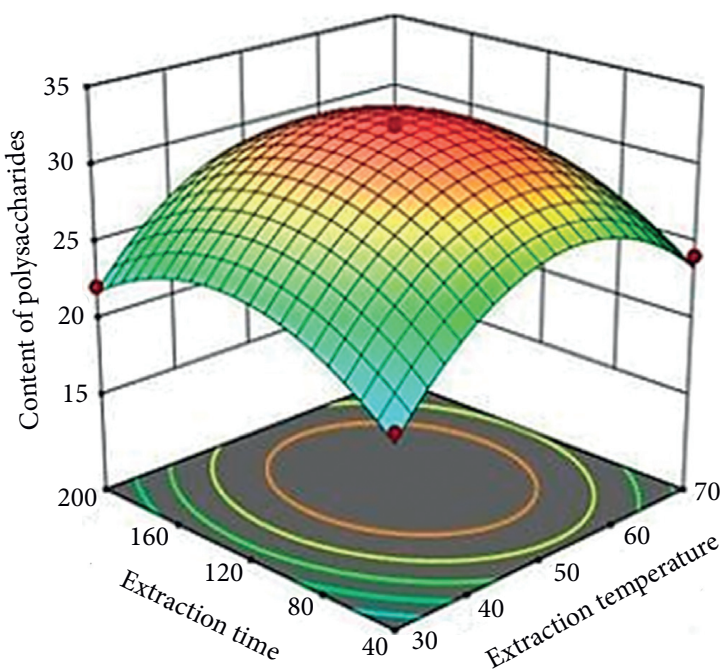

(b)

Figure 5: Simultaneous effect of extraction temperature and extraction time on the content of polysaccharides.

polysaccharides structure [34]. In addition, glycosidic bonds might be also represented in the relatively weak absorption peaks at $1620 \mathrm{~cm}^{-1}$ [35]. Moreover, the stretching vibration of $879 \mathrm{~cm}^{-1}$ referred to the absorption of $\beta$-D-glucose with the pyranose form $[35,36]$. The other bands observed at 1086,1044 , and $879 \mathrm{~cm}^{-1}$ were characteristic absorptions of to $\beta$ - $(1,3),(1,6)$-D-glucan [37].

3.4. Gel Permeation Chromatography. The molecular weights $(\mathrm{Mw})$, number average molecular weights $(\mathrm{Mn})$, and corresponding polydispersity index (PDI) were determined by GPC. The results showed that the Mw and Mn values were of $2.6843 \times 10^{3}$ and $1.6961 \times 10^{3} \mathrm{Da}$, respectively, with the PDI value of 1.5826 . The PDI is a measure of broadness of molecular weight distribution and the PDI of a polymer is calculated as the ratio of weight average by number average molecular weight [38]. It was stated that the lower $\mathrm{Mw}$ polysaccharides would have fairly narrow molecular weight distribution (MWD) and PDI of 1 to 1.5, whereas the higher Mw polysaccharides are generally regarded as having broad MWD and large PDI [39]. The PDI value of 1.5826, which was higher than 1.5 , may be caused by natural product as most natural occurring polysaccharides illustrated high PDI 


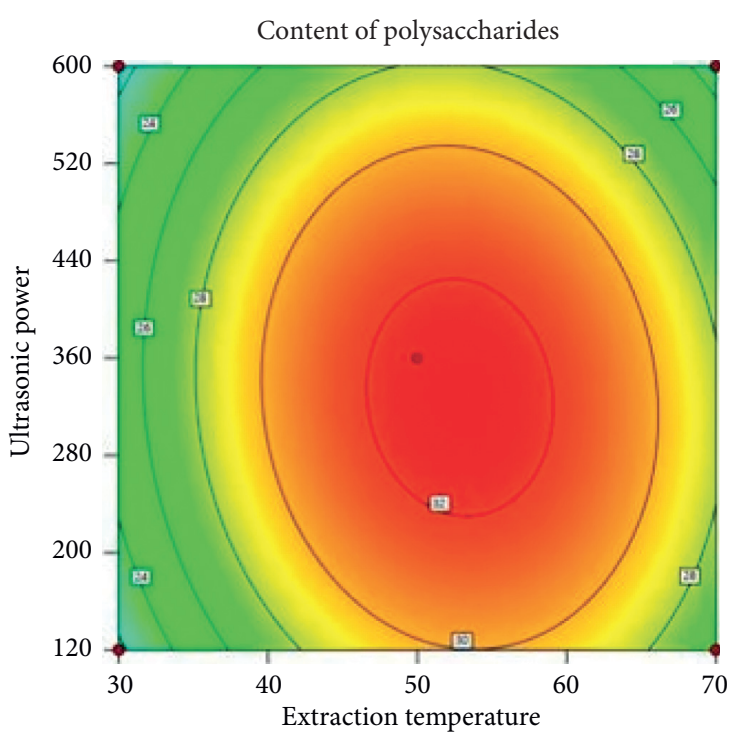

(a)

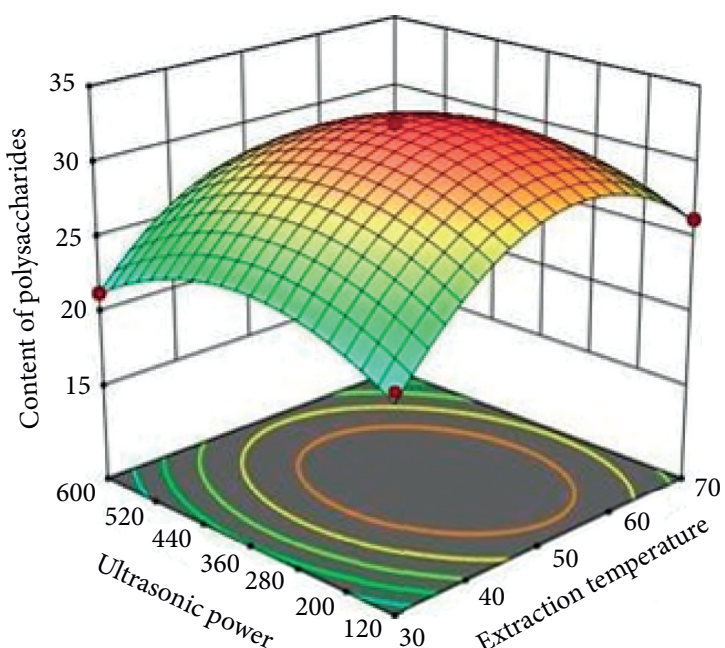

(b)

FIGURE 6: Simultaneous effect of extraction temperature and ultrasonic power on the content of polysaccharides.

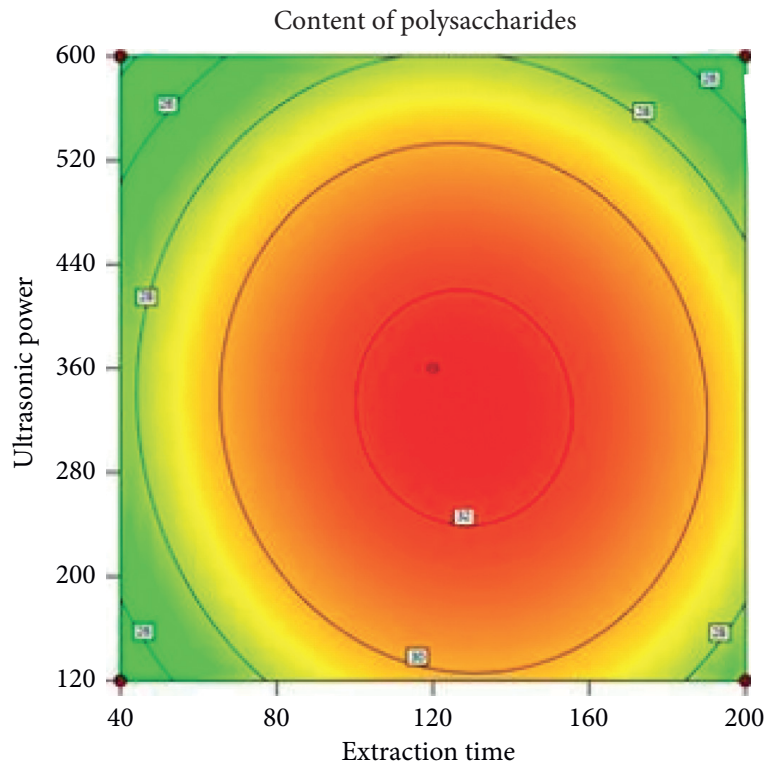

(a)

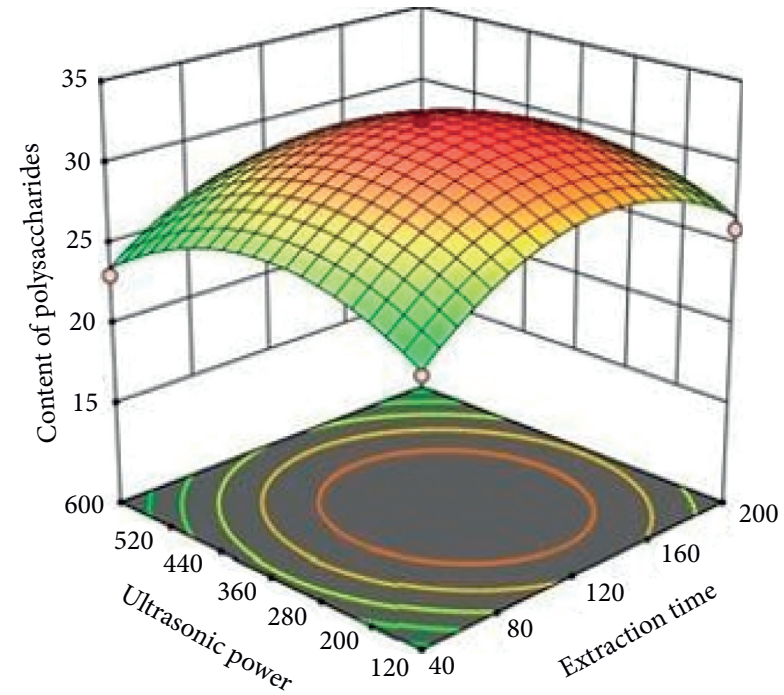

(b)

FIGURE 7: Simultaneous effect of extraction time and ultrasonic power on the content of polysaccharides.

TABle 4: Predicted and experimental optimum extraction conditions.

\begin{tabular}{lccccc}
\hline & $\mathrm{pH}$ & Extraction temperature $\left({ }^{\circ} \mathrm{C}\right)$ & Extraction time (min) & Ultrasonic power $(\mathrm{W})$ & $\begin{array}{c}\text { Content of polysaccharides } \\
(\mathrm{mg} / \mathrm{g})\end{array}$ \\
\hline Predicted conditions & 8.12 & 52.78 & 127.69 & 325.99 & 32.63 \\
Experimental conditions & 8.00 & 53 & 128.00 & 360.00 & 32.08 \\
\hline
\end{tabular}

value $[14,40]$. Basically, MWD refers to the amounts of component polymers making up a polymer and is essential for microstructural quality description of a polymer [41, 42].
In addition, according to previous studies, polysaccharide was recorded with the $\mathrm{Mn}$ value of $1013 \times 10^{3} \mathrm{Da}$ extracted from the fruiting bodies of Ganoderma atrum while from 


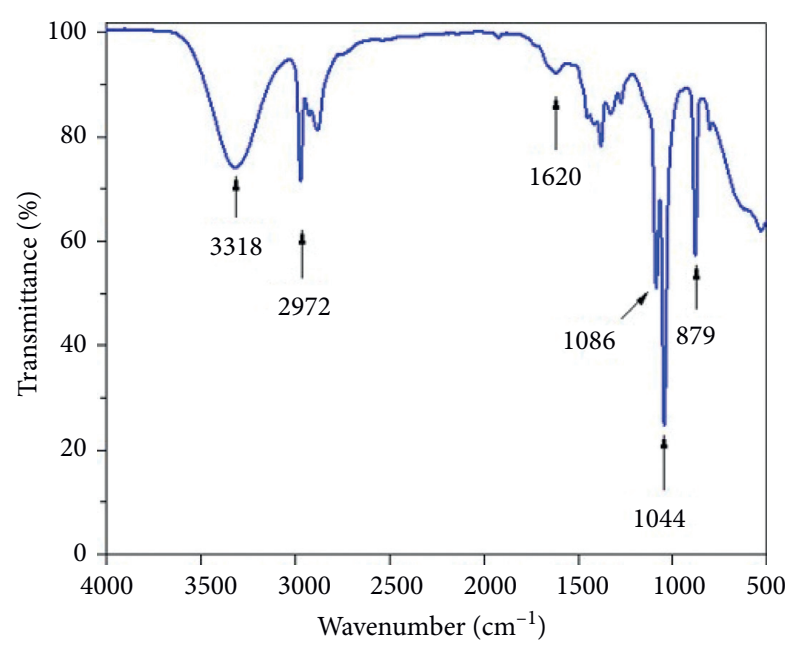

FIGURE 8: FT-IR spectra of polysaccharides.

TABle 5: $\mathrm{IC}_{50}$ values of the extract.

\begin{tabular}{lccc}
\hline & \multicolumn{3}{c}{$\mathrm{IC}_{50}$ value $(\mu \mathrm{g} / \mathrm{mL})$} \\
& $\mathrm{KB}$ & HepG2 & $\mathrm{Lu}$ \\
\hline The extract & $>512$ & $>512$ & $>512$ \\
Ellipticine & 0.45 & 0.38 & 0.41 \\
\hline
\end{tabular}

G. lucidum by using ultrasonic-aid extraction, polysaccharides with the Mn values of $1.926 \times 10^{3} \mathrm{Da}$ and $1086 \times 10^{3} \mathrm{Da}$ could be extracted $[43,44]$. These reported results were higher than that obtained in this study. Therefore, it could be suggested that the employment of ultrasound wave and enzyme could have influence on structures of long chain polysaccharides in the sample.

3.5. Anticancer Activities of Extracts. The test results of anticancer activity of the extract from G. lucidum on three lines of KB, HepG2, and Lu cancer cells are illustrated in Table 5. It can be seen from Table 5 that content of polysaccharides did not have significant influence on these cancer cell lines. At the same time, ellipticine showed strong cytotoxic activities with low $\mathrm{IC}_{50}$ values $(<0.50 \mu \mathrm{g} / \mathrm{mL})$. Nevertheless, according to previous study, the anticancer abilities of polysaccharides extracted from G. lucidum were not based on direct cytotoxicity effect of polysaccharides on cell lines. It is reported that polysaccharides showed the low anticancer activities against breast cancer cell lines, with a concentration of $50 \mu \mathrm{g} /$ $\mathrm{mL}$, but only $4.81 \%$ was inhibited. However, in the presence of polysaccharides and macrophages (cells of the immune system), polysaccharides were able to enhance the activity of macrophages and the inhibitory ability of cancer cells was significantly increased to $38 \%$ at the same concentration of $50 \mu \mathrm{g} / \mathrm{mL}$ [44]. Therefore, polysaccharides could be regarded as potential anticancer agents due to their boosting of the immune system ability. Meanwhile, cytotoxic effects on cancer cell lines remained unclear. Therefore, polysaccharides have poor cytotoxic effects on three cancer cell lines including $\mathrm{KB}, \mathrm{HepG}$, and Lu [44].

\section{Conclusions}

In this study, by using UAEE, polysaccharides were extracted from G. lucidum with the employment of the RSM and Box-Behnken design under the researched effects of $\mathrm{pH}$, extraction temperature, extraction time, and ultrasonic power. According to ultraviolet-visible spectroscopy analysis, the maximum content of polysaccharides in the extract was $32.08 \mathrm{mg} / \mathrm{g}$ under optimal conditions of enzyme concentration of $3 \%, \mathrm{pH}$ of 5.5 , extraction temperature of $45^{\circ} \mathrm{C}$, extraction time of $30 \mathrm{~min}$, and ultrasonic power of $480 \mathrm{~W}$. By using GPC technique, the Mw and Mn values of polysaccharides in the extract were of $2.6843 \times 10^{3}$ and $1.6961 \times 10^{3} \mathrm{Da}$, respectively, with the PDI value of 1.582 . The extract under these conditions was then evaluated for anticancer activities by (3-(4,5-dimethylthiazol-2-yl)-2,5diphenyltetrazolium bromide) assay, showing that the $\mathrm{IC}_{50}$ values were of more than $512 \mu \mathrm{g} / \mathrm{mL}$ for three cancer cell lines. Therefore, UAEE could be considered as an appropriate and effective extraction method for polysaccharides from G. lucidum.

\section{Data Availability}

The data used to support the findings of this study are included within the article.

\section{Conflicts of Interest}

The authors declare that they have no conflicts of interest.

\section{Acknowledgments}

This research was funded by Vietnam National UniversityHo Chi Minh City (VNU-HCM) under grant no. B2019-2002. The authors acknowledge the support of time and facilities from Ho Chi Minh City University of Technology (HCMUT), VNU-HCM for this study.

\section{References}

[1] S.-T. Chang and J. A. Buswell, "Ganoderma lucidum (curt.: Fr.) P. Karst. (Aphyllophoromycetideae)-a mushrooming medicinal mushroom," International Journal of Medicinal Mushrooms, vol. 1, no. 2, pp. 139-146, 1999.

[2] J. Ying, Y. Xu, and Y. Wang, Icons of Medicinal Fungi from China, Science Press, Beijing, China, 1987.

[3] S. C. Jong and J. M. Birmingham, "Medicinal benefits of the mushroom Ganoderma," Advances in Applied Microbiology, vol. 37, pp. 101-134, 1992.

[4] C. Hobbs, Medicinal Mushrooms: An Exploration of Tradition, Healing, \& Culture, Book Publishing Company, New York, NY, USA, 2002.

[5] D. J. Mckenna, K. Jones, K. Hughes, and V. M. Tyler, Botanical Medicines the Desk Reference for Major Herbal Supplements, Routledge, Milton Park, UK, 2002.

[6] K. Deepalakshmi and S. Mirunalini, "Therapeutic properties and current medical usage of medicinal mushroom: Ganoderma lucidum," International Journal of Pharmaceutical Sciences and Research, vol. 2, no. 8, 2011. 
[7] W. SP, "Reishi or lingzhi (Ganoderma lucidum)," in Encyclopedia of Dietary Supplements, pp. 603-622, Marcell Dekker, New York, NY, USA, 2015.

[8] Y. Gao, S. Zhou, G. Chen, X. Dai, and J. Ye, "A phase I/II study of a Ganoderma lucidum (curt.: Fr.) P. Karst. extract (ganopofy) in patients with advanced cancer," International Journal of Medicinal Mushrooms, vol. 4, no. 3, p. 8, 2002.

[9] V. E. Ooi and F. Liu, "Immunomodulation and anti-cancer activity of polysaccharide-protein complexes," Current $\mathrm{Me}$ dicinal Chemistry, vol. 7, no. 7, pp. 715-729, 2000.

[10] Y.-Y. Wang, K.-H. Khoo, S.-T. Chen, C.-C. Lin, C.-H. Wong, and C.-H. Lin, "Studies on the immuno-modulating and antitumor activities of Ganoderma lucidum (Reishi) polysaccharides: functional and proteomic analyses of a fucoseContaining glycoprotein fraction responsible for the activities," Bioorganic \& Medicinal Chemistry, vol. 10, no. 4, pp. 1057-1062, 2002.

[11] S. P. Wasser, "Medicinal mushrooms as a source of antitumor and immunomodulating polysaccharides," Applied Microbiology and Biotechnology, vol. 60, no. 3, pp. 258-274, 2002.

[12] T. Hosokawa, S. Inui, and S. I. Murahashi, "Ganoderic acid T and Z: cytotoxic triterpenes from Ganoderma lucidum," Tetrahedron Letters, vol. 24, pp. 1081-1084, 1983.

[13] C.-N. Lin, W.-P. Tome, and S.-J. Won, "Novel cytotoxic principles of formosan Ganoderma lucidum," Journal of Natural Products, vol. 54, no. 4, pp. 998-1002, 1991.

[14] M. Q. Guo, X. Hu, C. Wang, and L. Ai, "Polysaccharides: structure and solubility," Solubility of Polysaccharides, IntechOpen, London, UK, 2017.

[15] S. C. O. Ugbolue, "Testing, product evaluation and quality control of polyolefins," in Polyolefin Fibres, pp. 313-338, Woodhead Publishing, Sawston, UK, 2017.

[16] G. Giridhar, R. K. N. R. Manepalli, and G. Apparao, "Chapter 3-size- exclusion chromatography," in Thermal and Rheological Measurement Techniques for Nanomaterials Characterization, pp. 51-65, Elsevier, Amsterdam, Netherlands, 2017.

[17] A. M. Staub, "Removeal of protein-sevag method," Methods in Carbohydrate Chemistry, vol. 5, pp. 5-6, 1965.

[18] T. Q. Hoa, "Extraction of polysaccharides from lingzhi by ultrasonic-assisted enzymatic method," Vietnam Journal of Science and Technology, vol. 56, no. 4A, p. 171, 2018.

[19] K. Yang, Y. Zhang, M. Cai et al., "In vitro prebiotic activities of oligosaccharides from the by-products in Ganoderma lucidum spore polysaccharide extraction," RSC Advances, vol. 10, no. 25, pp. 14794-14802, 2020.

[20] X. Han, J. Li, and Z. Ying, "Ultrasound-assisted extraction of polysaccharides from mulberry leaves," Food Chemistry, vol. 127, no. 3, pp. 1273-1279, 2011.

[21] Z. Erbay and F. Icier, "Optimization of hot air drying of olive leaves using response surface methodology," Journal of Food Engineering, vol. 91, no. 4, pp. 533-541, 2009.

[22] F. Chen, Y. Sun, G. Zhao et al., "Optimization of ultrasoundassisted extraction of anthocyanins in red raspberries and identification of anthocyanins in extract using high-performance liquid chromatography-mass spectrometry," Ultrasonics Sonochemistry, vol. 14, no. 6, pp. 767-778, 2007.

[23] L. Wang, F. Liu, T. Li, D. Liu, Y. Xu, and Y. Yang, "Enzyme assisted extraction, purification and structure analysis of the polysaccharides from naked pumpkin seeds," Applied Sciences, vol. 8, no. 10, p. 1866, 2018.

[24] Y. Xu, L. Zhang, Y. Yang, X. Song, and Z. Yu, "Optimization of ultrasound-assisted compound enzymatic extraction and characterization of polysaccharides from blackcurrant," Carbohydrate Polymers, vol. 117, pp. 895-902, 2015.

[25] Y. Liu, G. Gong, J. Zhang et al., "Response surface optimization of ultrasound-assisted enzymatic extraction polysaccharides from Lycium barbarum," Carbohydrate Polymers, vol. 110, pp. 278-284, 2014.

[26] N. Liao, J. Zhong, X. Ye et al., "Ultrasonic-assisted enzymatic extraction of polysaccharide from Corbicula fluminea: characterization and antioxidant activity," LWT - Food Science and Technology, vol. 60, no. 2, pp. 1113-1121, 2015.

[27] X. Qin, X. Fan, L. Zhang, H. Zheng, C. Zhang, and J. Yuan, "Extraction, purification, and structure characterization of polysaccharides from Crassostrea rivularis," Food Science \& Nutrition, vol. 6, no. 6, pp. 1621-1628, 2018.

[28] M. Carail, A.-S. Fabiano-Tixier, A. Meullemiestre, F. Chemat, and C. Caris-Veyrat, "Effects of high power ultrasound on allE- $\beta$-carotene, newly formed compounds analysis by ultrahigh-performance liquid chromatography-tandem mass spectrometry," Ultrasonics Sonochemistry, vol. 26, pp. 200209, 2015.

[29] K. Assami, S. Chemat, B. Y. Meklati, and F. Chemat, "Ultrasound-assisted aromatisation with condiments as an enabling technique for olive oil flavouring and shelf life enhancement," Food Analytical Methods, vol. 9, no. 4, pp. 982-990, 2016.

[30] T. J. Mason, L. Paniwnyk, and J. P. Lorimer, "The uses of ultrasound in food technology," Ultrasonics Sonochemistry, vol. 3, no. 3, pp. S253-S260, 1996.

[31] Y. Hoshino, T. Kawasaki, and Y. Okahata, "Effect of ultrasound on DNA polymerase reactions: monitoring on a 27 $\mathrm{MHz}$ quartz crystal microbalance," Biomacromolecules, vol. 7, no. 3, pp. 682-685, 2006.

[32] H. Feng, G. V. Barbosa-CÃ $¡$ novas, and J. Weiss, Ultrasound Technologies for Food and Bioprocessing, Springer, New York, NY, USA, 2011.

[33] B. K. Tiwari, C. P. O'Donnell, and P. J. Cullen, "Effect of sonication on retention of anthocyanins in blackberry juice," Journal of Food Engineering, vol. 93, no. 2, pp. 166-171, 2009.

[34] M. Shi, Z. Zhang, and Y. Yang, "Antioxidant and immunoregulatory activity of Ganoderma lucidum polysaccharide (GLP)," Carbohydrate Polymers, vol. 95, no. 1, pp. 200-206, 2013.

[35] Y. Kan, T. Chen, Y. Wu, J. Wu, and J. Wu, "Antioxidant activity of polysaccharide extracted from Ganoderma lucidum using response surface methodology," International Journal of Biological Macromolecules, vol. 72, pp. 151-157, 2015.

[36] A. Ai-lati, S. Liu, Z. Ji, H. Zhang, and J. Mao, "Structure and bioactivities of a polysaccharide isolated fromGanoderma lucidumin submerged fermentation," Bioengineered, vol. 8, no. 5, pp. 565-571, 2017.

[37] A. N. M. Synytsya, "Structural analysis of glucans," Annals of Translational Medicine, vol. 2, no. 2, 2014.

[38] A. Shrivastava, Introduction to Plastics Engineering, William Andrew, Norwich, UK, 2018.

[39] A. Striegel and J. D. Timpa, "Molecular characterization of polysaccharides dissolved in Me2NAc-LiCl by gel-permeation chromatography," Carbohydrate Research, vol. 267, no. 2, pp. 271-290, 1995.

[40] X. Zeng, P. Li, X. Chen et al., "Effects of deproteinization methods on primary structure and antioxidant activity of Ganoderma lucidum polysaccharides," International Journal of Biological Macromolecules, vol. 126, pp. 867-876, 2019.

[41] D. V. Rosato, Plastics Engineered Product Design, Elsevier Science, Amsterdam, Netherlands, 2003. 
[42] C. Zhang, X. Chen, Z. Shao, C. Xu, and J. Wang, "Simulation and optimization of the molecular weight distribution in a non-ideal polymerization reactor," Computer Aided Chemical Engineering, vol. 38, pp. 565-570, 2016.

[43] Y. Chen, M.-Y. Xie, S.-P. Nie, C. Li, and Y.-X. Wang, "Purification, composition analysis and antioxidant activity of a polysaccharide from the fruiting bodies of Ganoderma atrum," Food Chemistry, vol. 107, no. 1, pp. 231-241, 2008.

[44] L. Zhao, Y. Dong, G. Chen, and Q. Hu, "Extraction, purification, characterization and antitumor activity of polysaccharides from Ganoderma lucidum," Carbohydrate Polymers, vol. 80, no. 3, pp. 783-789, 2010. 